\title{
Pequena Miss Sunshine: para além de uma subjetividade exterior
}

\author{
Rosa Maria Bueno Fischer*
}

Resumo: $\mathrm{O}$ artigo discute as relaçôes entre cultura do sucesso e sexualidade, com foco na infância - tema caro às diferentes mídias, como a televisão e o cinema. Faz-se uma análise do filme Pequena Miss Sunshine, a partir de autores como Foucault, Alain Badiou, Ismail Xavier e Jurandir Costa, com ênfase nos conceitos de modos de subjetivação, imagem fílmica e subjetividade exterior. $\mathrm{O}$ objetivo é pensar questôes de gênero e sexualidade na cultura do espetáculo, a partir de uma narrativa cinematográfica em que tais valores são questionados. A ênfase é dada à análise do olhar e do corpo infantil, na figura da personagem Olive, de modo a pensar a gestualidade própria da criança, em seu silêncio, enigma e mistério, mais do que mera revelação de sentidos. O texto aponta que tal exercício pode sugerir outros modos de pensar as relaçốes entre mídia, infância e questôes de gênero e sexualidade.

Palavras-chave: cinema; relaçóes de gênero; corpo; sexualidade; infância.

\section{Little Miss Sunshine: beyond external subjectivity}

Abstract: This article explores the relations between the culture of success and sexuality, with a focus on childhood as an important issue for the different kinds of media, such as television and the cinema. An analysis of the movie Little Miss Sunshine is developed, with the use of theoretical references from Foucault, Alain Badiou, Jurandir Costa and Ismail Xavier, about the concepts of audiovisual images, ways of subjectivation and external subjectivity. The aim of the study is to reflect on gender and sexuality issues in a spectacle culture, from a movie narrative in which such values are questioned. There is an analysis of children's bodies and their way of seeing the world, as expressed by the character Olive, with gestures, silence and mystery, rather than a revelation of senses. Such practices may suggest other ways of considering the relations between media, childhood and gender and sexuality issues.

Key words: cinema; gender relations; body, sexuality; childhood.

Que vazios instauram as imagens da criança no cinema, especificamente no filme Pequena Miss Sunshine? Que vazios nos convocam a olhar de um outro

* Pesquisadora do CNP q e professora da Facul dade de Educação e do Programa de Pós-Graduação em Educação da Universidade Federal do Rio Grande do Sul (UFRGS). Brasil. rosabfischer@terra.com.br

1. Produção de 2006, dos norte-americanos Jonathan Dayton e Valerie Faris, foi premiada como melhor filme do Festival de Cinema Norte-Americano de Deauville, na França. Concorreu ao 
modo o corpo infantil feminino, na personagem Olive, para além daquilo que de certa forma já está dado: uma menina "gordinha", mas "boa", versus meninas "más", magrinhas, identificadas com o status quo de uma sociedade norte-americana fake, em que os processos de conformação dos corpos das mulheres acabam por fazê-las todas absolutamente iguais, cópias adultas e infantis de um mesmo modelo? Como escapar de uma análise sobre corpo e sexualidade cuja base é a afirmação de uma crítica já sabida de antemão e que pouco acrescenta ao debate sobre as relações de gênero na educação ${ }^{2}$ ?

Talvez possamos nos deixar tomar pelas sequiências da narrativa de Pequena Miss Sunshine, as imagens-tempo e as imagens-movimento desse filme, no sentido de deixar-nos ser olhados pelas imagens oferecidas pelo cineasta, pelos atores, pela montagem e permitir que esse ato de entrega possa talvez pensar a potência afirmativa da criança ${ }^{3}$ - no caso, a personagem Olive - que nos olha, desde a primeira cena do filme, em big close, por meio de uma camada interminável de "lentes": nosso próprio olhar; a projeção na tela do cinema; os enormes óculos da personagem; a tela da TV que ela observa; a ação do controle remoto acionado pela menina, que faz retroceder e repetir imagens; o reflexo da cena do vídeo no vidro dos óculos de Olive; o olhar das misses na cena televisiva, dirigidos às câmeras, e assim por diante. Essa cena inicial já sugere, por si mesma, uma sobreposição de olhares, um cruzamento que convida a ver talvez um pouco mais do que o óbvio - para usar uma categoria de análise proposta por Roland Barthes (1990), em O óbvio e o obtuso.

Já sabemos que as questôes de gênero e sexualidade são inseparáveis de um tempo e de uma sociedade muito específicos: ou seja, ficaremos no nível do sentido "óbvio", se nos contentarmos com uma análise que se limita a pontuar os problemas da família Hoover, do filme, nos quais predominam, de um lado, as dificuldades financeiras e, de outro, os sonhos construídos pela cultura norte-americana - distribuídos fartamente em escala mundial - do sucesso indivi-

Oscar de melhor filme, em 2007. Narra a saga de uma família de Novo México, que viaja mais de mil quilômetros até a Califórnia, levando a menina Olive, de 7 anos, para participar de um concurso de beleza infantil.

2. Neste artigo, tenho como referência estudos de gênero, educação e sexualidade, feitos no Brasil, por estudiosas como Guacira Louro e Dagmar Meyer, do GEERGE - Grupo de Estudos de Educação e Relaçōes de Gênero, da UFRGS, além de inúmeros outros pesquisadores que, no Brasil e em outros países, dedicam-se a essa temática. Não discuto, porém, no interior do texto, conceitos que já estão suficientemente tratados em livros como Corpo, genero e sexualidade (Meyer; Soares, 2004); Currículo, género e sexualidade (Louro, 200 I), entre tantos outros textos. Valho-me também da contribuição de estudiosas como Judith Butler, especialmente os estudos sobre gênero em que a autora utiliza a teoria de Michel Foucault (Butler, 1989).

3. Ver, sobre esse tema, a Tese de Doutorado de Fabiana de Amorim Marcello, Cinema e imagem no olhar sem corpo do cinema (Marcello, 2008). 
dual e da disputa pelo reconhecimento de uma imagem de vencedor, neste caso, centralizada no concurso mirim de beleza. Se isso já está dado, o que restaria ao analista de um filme como esse, dentro de uma outra perspectiva? Como olhar e deixar-se ser olhado, em Pequena Miss Sunshine, de modo a aceitar diferentes convocações: a convocação da menina Olive, a do adolescente em greve de silêncio Dwayne, a do suicida gay Frank, a do fracassado otimista Richard, a do hedonista de terceira idade Edwin, a da apaziguadora mãe Sheryl?

O sentido óbvio não será descartado, certamente, pois remete a um conjunto de dados da própria emergência do filme, não por acaso iniciado no ano 2001, nos Estados Unidos, um país então acuado e ao mesmo tempo ainda orgulhoso de si mesmo, após o atentado ao World Trade Center, em Nova York. Remete também ao conflito permanente de uma sociedade que se mantém conservadora, em muitos setores, mas que foi uma das primeiras a colocar em debate diferenças e polêmicas relacionadas a gênero e sexualidade. Mas é preciso ir além, quando nos debruçamos sobre imagens cinematográficas: não se trata de interpretar cada gesto dos personagens, cada fala, e encontrar neles, finalmente, uma explicação causal, a representação de algo que seria exterior à narrativa e às imagens do filme analisado, fatos comprovadores de uma tese que estariam ali expostos, como reprodução de uma dada realidade.

De acordo com o que nos ensina Ismail Xavier, "nada há por trás das imagens, elas valem como efeitos-de-superfície, imagem remetendo a imagem, fluxo de simulacros" (Xavier, 2003, p. 50). Essa é também a proposta de Foucault (2001a; 1986), para uma análise dos discursos: não se trata de acordar enunciados imersos num suposto sono, ato que nos levaria à essência de algo, à verdade dos fatos, a candentes revelaçôes. Nesse sentido, o cinema é exemplar, diz Xavier: não há como defender, ainda outra vez, que as narrativas esconderiam verdades a serem descobertas, pois o que um filme faz é, em suma, organizar acontecimentos segundo um certo ângulo de observação que, por sua vez, dirige o nosso olhar. E é assim que, em Pequena Miss Sunshine, vamos partilhando com a família Hoover cada modo de os personagens olharem a si mesmos, num jogo de espelhos e telas - especialmente nas cenas iniciais da narrativa. Não só a menina Olive se olha ao espelho, fixando o olhar na tela da TV e reproduzindo a gestualidade das misses; também seu irmão adolescente, Dwayne, mesmo tendo marcado em seu corpo, pelo voto de silêncio, a resistência ao american way of life do século XXI pós-Torres-Gêmeas, exercita a musculatura diante do espelho, em preparação para um futuro como piloto de aviação; nem o avô, consumidor de heroína, deixa de ser mostrado duplamente em imagem especular.

Parece-me que tal recurso cenográfico, os jogos de espelho, e todas as demais escolhas narrativas teriam o poder de conduzir o espectador, de tal forma 
que este é chamado a completar as cenas, a "pensar" junto com os personagens - no caso que nos interessa aqui -, quanto a suas próprias opções de vida sexual, de papéis de homens e mulheres, de relaçôes de gênero e de usos do próprio corpo. Escreve Ismail Xavier:

Cercado de imagens, vejo-me inscrito pela media numa segunda natureza, num processo que implica um cotejo de pontos de vista muito peculiar, que me afasta, por exemplo, do enfrentamento próprio da relação pessoal, intersubjetiva. Esta se constitui pela devolução do olhar e nela repercute o que nos diz o poeta Antonio Machado: o olho que vejo é olho porque me vê, não porque o vejo. Diante do aparato construtor de imagens, minha interação é de outra ordem: envolve o olho que não vejo e que não me vê, que é olho porque substitui o meu, porque me conduz de bom grado ao seu lugar para eu enxergar mais... ou talvez menos (Xavier, 2003, p. 57).

Penso que em Pequena Miss Sunshine esse olho que vê por nós, que substitui o nosso olho, mas não o descarta (pelo contrário), esse olho, no filme, convidanos a enxergar mais. A enxergar mais sobre a infância e sua relação com sonhos sonhados antes dela, feitos para ela - como o do concurso de beleza; sobre a sensualidade ensaiada e ao mesmo tempo lúdica e afetiva, a misturar infância e velhice - presente nas aulas de coreografia dadas pelo avô à menina; sobre a relação da criança com as diferentes opçôes sexuais da sociedade em que vive, que não se separam da proximidade com a morte - o que é evidente nas indagaçôes da menina ao tio suicida e gay, bem como nas recomendaçôes do avô, personagem que morre no meio da travessia, ao neto adolescente, quanto à importância de desfrutar de muitas mulheres, desde cedo, muitas e ao mesmo tempo.

Talvez de fato estejamos, como nos ensina Alain Badiou ao aproximar o cinema da filosofia - ou do convite ao pensamento -, diante de um filme que, na sua simplicidade, na sua condição de cinema alternativo norte-americano, sugere que pensemos sobre problemas de corpo e sexualidade, tendo como centro a figura infantil feminina, a partir de uma questão que se poderia chamar de ética. Para Badiou, o cinema não seria apenas uma arte de figuras do tempo e do espaço, figuras do mundo exterior, mas principalmente uma arte "das grandes figuras da humanidade em ação, um tipo de cena universal da ação. São formas fortes, encarnadas, dos grandes valores que se discutem em um dado momento" (Badiou, 2004, p. 34, tradução minha).

Nosso mundo carece de heróis, diz Badiou, e o cinema continua insistindo em criar personagens com preocupação moral, gente que entra no combate contra "o mal" - o que pode, na maioria dos produtos midiáticos, assumir as 
repetitivas formas classificatórias e preconceituosas ensinadas pelo "cinemão" de Hollywood; mas pode, igualmente, comover-nos mais profunda e complexamente, na medida em que, num mundo sem heróis sólidos, sem referências fortes, apresenta a grandes públicos algumas figuras típicas, a vivenciarem graves conflitos da vida humana. Ainda hoje, no cinema, continuamos a falar, como escreve Badiou, da "coragem, da justiça, da paixão, da traiçáo" (Badiou, 2004 , p. 35), o que, segundo o autor, poderia ser visto como uma herança do teatro grego.

A saga da família Hoover, viajando por mais de mil quilômetros numa Kombi aos pedaços, do Novo México à Califórnia, é a saga de seis anti-heróis americanos que, talvez por essa condição de serem "menos" na sociedade em que vivem, dão-se a ver como heróis, na medida em que põem a nu um por um os valores já cristalizados dessa mesma sociedade. No centro dessa singular e mínima revolução, está a perplexidade sobre o que fazer de nossos corpos e de nossa sexualidade. A menina obcecada por concursos de beleza é a antítese de tudo o que se espera de alguém que deseja participar de uma disputa nessa área: os grandes óculos e o corpo fora dos padrões de magreza não chegam a ser explicitamente contestados por ninguém na família, a não ser pelo pai, na cena do sorvete, durante o café da manhã em plena estrada. A narrativa é conduzida de tal forma que também nós, espectadores, não reagimos ao desejo da menina - apenas acompanhamos, atentos, o desenrolar de uma trajetória destinada ao fracasso.

Acontece, porém, que esse mesmo corpo fora do lugar, de uma menina fora do lugar, aprende - com o avô, ele também deslocado e à margem - o prazer de dançar e de experimentar a própria sensualidade. Os diretores do filme, delicada e contundentemente, interpelam-nos no sentido de fazer-nos atentos ao visível - ao que "está ali", nas imagens daquelas sequiências -, oferecendo-nos ao mesmo tempo, porém, material que nos joga para fora do que está dado. Ou seja: impulsionando-nos para o que ali tem potência de se tornar de alguma forma visivel (Xavier, 2003, p. 57). Em outras palavras, estamos, no filme, diante de problemas conhecidos de nós todos - como o do convite à exposição do corpo, de crianças e de adultos, especialmente de mulheres, desde que dentro de determinados padrões de peso e de medida; ou o da incitação a manifestações de uma sensualidade um tanto fora de lugar de crianças - meninas, de modo geral - que, num país como o Brasil, são aplaudidas candidamente por adultos orgulhosos das artes por vezes pornográficas de corpos que apenas iniciam uma experimentação lúdica de si mesmos. Em Pequena Miss Sunshine, a opção é fazer ver o que aí está e, simultaneamente, fazer ver mais - na medida em que, por exemplo, o striptease da cena final, no momento do show de Olive durante o concurso, aparece bem mais como crítica à violência em relação aos 
corpos femininos infantis daquelas meninas penteadas e vestidas como barbies adultas e absolutamente fakes.

Esse paradoxo talvez confunda o espectador, na medida em que faz com que a sensualidade ensinada pelo avô à menina seja recebida não só como gesto afetivo do adulto, mas também como parte de um simples jogo dramático infantil. Ou seja, a própria condição de um corpo fora do lugar - porque não é magro elimina a chance de a dança supostamente erótica ser vista pelo espectador como um modo de adesão à erotização precoce de crianças, fato merecedor de tantas críticas por parte de estudiosas feministas ${ }^{4}$ e por parte de diferentes instituiçôes de proteção a crianças e adolescentes. Da mesma forma, a condição do tio Frank, gay e suicida, motivo de curiosidade por parte de Olive, recebe um tratamento inusitado, fora dos padrões midiáticos corriqueiros, pois a homossexualidade deixa de ser o "problema" maior, diante de outra questão bem mais séria para o personagem: a competição pelo título de ser o maior estudioso de Proust.

Jurandir Freire Costa, psicanalista que tem publicado vários textos sobre o que denomina "subjetividade exterior", apóia-se em Michel Foucault para falar sobre os anormais de nosso tempo; segundo o autor (Costa, 2004), os desviantes de nosso tempo, diferentemente daqueles do século XVIII e XIX, estudados por Foucault (2001b), não ameaçam a cultura por serem contra-exemplos de uma concepção de racionalidade humana. Nossos anormais, diz Costa, são fracos de vontade, são os estultos, numa sociedade em que predomina a personalidade somática. Entre eles estão os drogados, os dependentes de consumo, de sexo, de exercícios físicos, os que não conseguem controlar suas carências físicas, como os anoréxicos e bulímicos, os portadores de fobias, síndromes de pânico; também estão entre eles os estressados, os inibidos, os deformados como os obesos, os sedentários, os tabagistas, dentre tantos (Costa, 2004, p. 195-196). Toda a classificação tem como parâmetro o que o autor chama, foucaultianamente, de bioidentidades - identidades marcadas pelo corpo e o que dele se deseja no social.

Os cabelos exageradamente armados e os rostos excessivamente maquiados das meninas - cópias fiéis de suas mães - com as quais concorre Olive, embora ocupem apenas as cenas finais do filme, assumem uma força considerável na narrativa, exatamente por serem mostrados ao mesmo tempo em que toda a família Hoover, com exceção da menina, começa a perceber o engano de todo o investimento, da viagem, da aposta feita. Olive persiste, apresenta-se, homenageia o avô já morto e age "normalmente", desafiando a norma. O corpo fora do lugar e a coreografia com estereótipos de gestos sensuais (a imitação do ataque de uma tigresa, por exemplo, rugindo e avançando com as garras sobre

4. Ver a propósito, Felipe; Guizzo (2003). 
um suposto homem) enfrentam o estabelecido, num clímax antecedido de tensão que, por sua vez, propicia a crescente união daquela família de perdedores.

Desde o momento em que a velha Kombi tem a embreagem danificada e todos são obrigados a empurrar o carro, o grupo sofre uma transformação, e o mal-estar inicial parece aos poucos desfazer-se. Em voto de silêncio por nove meses, por exemplo, o adolescente Dwayne, que não larga o livro Assim falou Zaratustra, durante a travessia vem a saber que seu corpo carrega uma anormalidade: é daltônico - descoberta feita pela personagem Olive, a menina de sete anos cujo desejo, aliás, conduz toda a narrativa - o que determina a impossibilidade de realizar o sonho de ser piloto de aviação. É também ela que consegue trazer o irmão de volta, convencendo-o a seguir viagem - numa das cenas mais delicadas do filme. Ou seja, durante todo o filme, o que temos diante de nossos olhos são histórias, corpos, olhares, gestos que olham por nós, como diria Ismail Xavier, na medida em que nos oferecem pontos de vista sobre homens e mulheres; meninas e adolescentes; mulheres adultas e pessoas idosas; homossexuais; drogados; homens integrados à ordem dos vencedores como o pai Richard, que sonha publicar um best-seller de auto-ajuda com os nove passos necessários para jamais alguém chegar a ser um perdedor.

O filme interpõe-se entre nós e o mundo: oferece-nos, por exemplo, a imagem da mulher-mãe que, de alguma forma, cumpre um dos papéis facilmente identificáveis, de apaziguadora, de organizadora do "lar"; mas é essa mesma mulher, a personagem Sheryl, que oferece ao jantar pacotes de alimentos comprados prontos, sem nenhum convencional traço da feminilidade materna esperada; é essa mulher que pontua para os demais o "concreto", a "realidade" por exemplo, o fato de que seu irmão Frank tentou o suicídio e que é gay. Porém, é essa mesma mulher que assume com a filha de sete anos o sonho do concurso Pequena Miss Sunshine. A complexidade de cada um dos personagens, como Sheryl, produz algo diferente em nós, uma síntese ordenadora do mundo (e, junto, uma ruptura sensível), que generosamente nos confunde e surpreende, que se oferece de fato como uma verdadeira continuidade descontínua. Ou, como escreve Badiou, que nos mostra a não-oposição plena entre o contínuo e o descontínuo - no caso, quanto às relaçóes de gênero. Quando pensamos que estamos diante do perfeito papel da mulher tradicional norte-americana, no qual reconhecemos muito também da realidade da América Latina o mesmo papel questionado em filmes como Thelma \& Louise, por exemplo ${ }^{5}-$ , acontece de essa mulher não se mostrar em nada como a mocinha sonhadora,

\footnotetext{
5. Thelma \& Louise étambém um filme caracterizado como um road movie, à semelhança de Pequena Miss Sunshine, e foi lançado em 1991 , com direção de Ridley Scott e participação das atrizes Geena Davis e Susan Sarandon. A estudiosa de cinema e educação, Elizabeth Ellsworth, faz uma instigante análise de Thelma \& Louise no texto "Modos de Endereçamento" (Ellsworth, 200I).
} 
pois o romântico é seu marido Richard, professor de auto-ajuda, crente na ideologia do sucesso e daquele que vence pelas próprias forças.

O outro-criança, menina sonhadora e crítica; o outro-homem, intelectual frustrado e homossexual; o outro-mulher, dona de casa; o outro-homem, pai de família e fracassado; o outro-idoso, hedonista e drogado; o outro-adolescente e revoltado, em voto de silêncio - temos aí um exemplo do cinema no papel que Badiou tão bem caracterizou: o cinema como meio de nos apresentar o outro na sua relação com o mundo; mais do que isso, o cinema como modo de amplificar nossas possibilidades de pensar o outro (Badiou, 2004, p. 56). São várias as cenas em que as questóes de gênero e sexualidade são apresentadas para além das continuidades esperadas - e é nesse momento que emerge o outro, aquele que é diferente de nós, já que nos é de algum modo estranho, pois assim é exposto. O avô, por exemplo, é amoroso com a neta e, ao mesmo tempo, é o homem que foge ao esperado, que se droga, que faz sexo com várias mulheres simultaneamente, que desafia a instituição do asilo, que aconselha o neto adolescente a não perder a oportunidade de ter relação com mais de uma mulher e assim por diante.

Importa deixar claro que não se trata aqui de analisar representações, mas de compreender que há ali uma realidade efetivamente criada pelo cinema, por um cineasta, pelos diretores, os quais pensam por e com imagens. Daí a importância de nos atermos a imagens efetivamente produzidas - como a cena inicial do filme, o rosto em primeiríssimo plano da pequena Olive, seus enormes óculos e o brilho do olhar depositado sobre a tela da TV e o corpo das misses. Não há dúvidas: o cinema é feito de impurezas, como diz Badiou, a impureza de todas as condiçôes de produção do filme, os atores, o financiamento, as locaçôes, o cenário, a fotografia, o figurino, as câmeras, toda a equipe, o roteiro (Badiou, 2004). Mas há um trabalho de "purificação", de seleção, de eliminações, de escolhas - como a da cena acima descrita, ou a do aconchego de Olive junto ao irmão Dwayne, o ensaio do gesto de tigresa com o avô - cenas que se torna difícil descrever em toda a sua inteireza e em todos os efeitos que produzem em nós. Em muitas das passagens do filme, a alegria do olhar de Olive, a maneira como diz "Yes!", ao concordar plenamente com uma afirmação, são elementos narrativos que ultrapassam uma mera descrição que deles se possa fazer. São momentos que remetem ao sentido obtuso de que fala Roland Barthes (1990). São imagens que dizem respeito a "algo mais", imagens por vezes indescritíveis, mas que produzem em nós efeitos éticos e estéticos particulares, advindos talvez de uma rara simplicidade alcançada. São imagens que dão a pensar. São sentidos que não estão em qualquer lugar, em qualquer filme, em qualquer cena. Eles nos deixam em suspenso, eles dizem respeito ao descontínuo, não nos conduzem, como escreve Barthes, ao "espasmo do significado", mas 
configuram uma espécie de dobra — difícil de descrever — , por sobre as informaçôes e as significações de determinadas imagens.

Toda a complexidade do imaginário contemporâneo, de uma sociedade como a norte-americana, que atravessa fronteiras, certamente - esse é o material de que se serve o filme Pequena Miss Sunshine, particularmente no que se refere à elaboração de um pensamento sobre a infância feminina e sua relação com o mundo adolescente e adulto. Estão aí as informaçôes e as significaçôes de que num primeiro nível tratamos, ao analisar as imagens. Dessa complexidade, os diretores conseguiram extrair uma certa dose de pureza, como diria Badiou (ou alguns sentidos obtusos, como diria Barthes), na medida em que nos oferecem uma mediação, uma interposição de olhares, um ponto de vista que contempla a descontinuidade dos modos de ser homem, mulher, criança, adolescente, idoso; uma pureza atenta a questôes "impuras" como a pornografia, a exploração do corpo infantil e feminino, a violência da imposição de corpos, normatizados pela força de uma sociedade marcada por personalidades somáticas, pela subjetividade exterior, como nos alerta Jurandir Costa.

Diria que o conceito de modos de subjetivação, desenvolvido por Foucault nos últimos anos de sua produção - especialmente $\mathrm{em} A$ hermenêutica do sujeito (Foucault, 2004) -, poderia ser articulado às discussões de Barthes e Badiou sobre imagens do cinema, aqui utilizadas. Foucault, sem deixar de estar ocupado com a leitura crítica e política dos dispositivos de poder, que tanto o marcaram em sua trajetória acadêmica e existencial, concentra-se nesses últimos escritos em pensar as questôes éticas e estéticas da produção de si mesmo. Ele busca, nos filósofos da Antigüidade clássica grega e romana, fonte para pensar não mais prioritariamente o problema das diferentes formas de sujeição ou de assujeitamento, mas antes o tema dos modos de subjetivação. Estes, na leitura de Foucault, apontavam para práticas de si mesmo e práticas da verdade, nas quais estariam mais evidentes formas de liberdade do sujeito, construção de si mesmo como arte, como forma de fugir ao instituído e atuar da melhor forma como cidadão na pólis. Talvez se possa pensar que o cinema, partindo dos imaginários dominantes, das relaçôes dadas historicamente, das "impurezas" próprias de qualquer produção cinematográfica - ao criar imagens que ultrapassam os níveis informativos e simbólicos da comunicação, ao buscar atingir espaços de uma certa "pureza" e ao abrir espaço aos "sentidos obtusos" -, esteja também oferecendo material para o aperfeiçoamento de cada um de nós, no sentido grego do cuidado consigo mesmo (Foucault, 2004). Isso seria válido para o próprio processo de produção cinematográfica, como para o trabalho de pesquisa e análise das criaçôes audiovisuais ${ }^{6}$.

6. A propósito das relaçōes entre cinema, educação e formação ético-estética, ver Fischer (2007). 
Em síntese, a proposta deste texto foi explorar uma narrativa filmica recente, de repercussão internacional, caracterizada por soluções simples em termos de produção cinematográfica, mas que oferece amplo material para pensarmos nossa relação com as imagens audiovisuais - entendendo que estas se configuram como criação, como produção de um ponto de vista específico, e não como meras representaçôes, que nos encarregaríamos de interpretar, em busca de referentes "reais" e concretos. Aceitamos aqui a proposta de Badiou, de pensar o cinema como arte impura, como arte de massas, que pode sofrer, no caso dos filmes mais bem trabalhados, um processo de transformação, em busca talvez de uma "pureza provisória", caracterizada pela invenção de cenas, pelo desempenho de atores, pela arte da montagem e da sonorização. $\mathrm{O}$ imaginário das relações de gênero em nossa sociedade, os modos de construir o corpo da menina, as violências daí decorrentes constituíram, no caso de Pequena Miss Sunshine, ponto de partida para todo um trabalho de criação estética. Este, por sua vez, foi aqui discutido, na tentativa de mostrar como uma narrativa fílmica pode ser pensada para além de interpretaçôes e de análise de representaçôes, especificamente, sobre corpo, sexualidade e gênero.

\section{Referências bibliográficas}

BADIOU, Alain. El cine como experimentación filosófica. In: YOEL, Gerardo (Comp.). Pensar el cine 1. Imagen, ética y filosofia . Buenos Aires: Manantial, 2004, p. 23-81.

BARTHES, Roland. O óbvio e o obtuso. Trad. Lea Novaes. Rio de Janeiro: Nova Fronteira, 1990.

BUTLER, Judith. Foucault and the paradox of bodily inscriptions. The Joumal of Philosophie. Columbia University, Nova York, v. 85, n. 11, p. 601-607, 1989.

COSTA, Jurandir Freire. O vestígio e a aum. Corpo e consumismo na moral do espetáculo. Rio de Janeiro: Garamond, 2004.

ELLSWORTH, Elizabeth. Modos de endereçamento. In: SILVA, TomazTadeu (Org.). Nunca fomos humanos - nos rastros do sujeito. Belo Horizonte: Autêntica, 2001, p. 07-76.

FELIPE, Jane; GUIZZO, B. S. Erotização dos corpos infantis na sociedade de consumo. ProPosiçôes, v. 14, n. 3, p. 119-129, 2003.

FISCHER, Rosa Maria Bueno. Cinema e TV na formação ético-estética docente. Trabalho apresentado na 30a Reunião Anual da ANPEd (Associação de Pós-Graduação e Pesquisa em Educação), em Sessão Especial. Caxambu (MG): 2007. Texto disponível em: http:// www.an ped.org.br/reunioes $/ 30 \mathrm{ra} /$ sessoes_especiais/sessao $\% 20$ especial $\% 20$ \%20rosa\%20fischer\%20-\%20int.pdf. Acesso em 29/01/2008.

FOUCAULT, Michel. A arqueologia do saber. Trad. Luiz Felipe Baeta Neves. Rio de Janeiro: Forense, 1986. 
FOUCAULT, Michel. A hermenêutica do sujeito. Trad. Márcio Alves da Fonseca; Salma Tannus Muchail. São Paulo: Martins Fontes, 2004.

FOUCAULT, Michel. Estética: literatura e pintura, música e cinema. Ditos \& Escritos III. Trad. Inês Autran Dourado Barbosa. Rio de Janeiro: Forense, 2001a.

FOUCAULT, Michel. Os anomais. Trad. Eduardo Brandão. São Paulo: Martins Fontes, 2001b.

LOURO, G. Curriculo, gênero e sexualidade. Porto: Porto Editora. 2001.

MARCELLO, Fabiana de Amorim. Criança e imagem no olhar sem corpo do cinema. 2008.214 p. Tese (Doutorado em Educação). Faculdade de Educação, UFRGS.

MEYER, Dagmar; SOARES, Rosângela (Org.) Corpo, gênero e sexualidade. Porto Alegre: Mediação, 2004.

XAVIER, Ismail. O olhare a cena. São Paulo: Cosac \& Naify, 2003. 